\title{
Evaluation of Globally Operating Salesforce Staff by Multiple Attribute Decision Making Methods
}

\author{
Gabriela Polakova* \\ VSB-Technical University of Ostrava, Faculty of Economics, 70200 Ostrava, Czech Republic
}

\begin{abstract}
Business managers, globally sales executives operating worldwide, representing brands and good reputation of international companies are a special group of staff needing especially flexible working conditions to do their job all over the world. The evaluation and rewarding of their performance is globally linked to achieving business targets. How evaluate results of all involved staff working on different international markets as one set of so many variants and criteria with ensuring transparency, objectivity and fairness? The solution is found in multiple attribute decision methods (MADM). The aim of the paper is to evaluate a group of salesforce staff making international business world-wide by using MADM to identify and reward the best sales executives and at the same time manage to make them to feel be valued for their well-done work, efforts and achievements. Two methods of multiple attribute decision making were used for this evaluation - the Technique for Order of Preference by Similarity to Ideal Solution (TOPSIS) and the Weighted Sum Approach (WSA). The results of both methods were compared and the more suitable method for this universal application practicable world-wide in terms of the processing complexity and the user friendliness was chosen and recommended. The bonus scheme is based on a healthy competition for sales executives, on a motivation to grow up and gain better results to get additional special bonus beyond the standard rewards for meeting performance targets. Part of this papers is the proposal of flexible bonuses for reached positions in the ranking of evaluated employees.
\end{abstract}

\section{Introduction}

Generally bonus payments are linked to achievement of business targets. There are also elements related to achieving specific goals and to individual performance. Bonuses are intended to motivate employees to achieve performance improvements for the business. (But there is no evidence that this really takes place.) [1] Performance evaluation of employees is a complex task that must take into account various aspects and evaluation criteria. [2] Performance evaluation (PE) of employees is perceived as one of the most practical organisational challenges because of its influence on employees' retention, satisfaction and their future performance [3]. Proactive behaviour has been indirectly linked to effective selling, an assertion underpinned by a logic, which states that in a world of high competition

*Corresponding author: Gabriela.polakova@post.cz 
and choice, the passive, reactive seller is unlikely to do as well as his or her more proactive counterpart. Yet, little direct empirical evidence exists to substantiate this link [4]. A theory of salesforce compensation plans is presented where the sales of a product depend not only on the salesperson's effort but also on the uncertainty in the selling environment [5]. Basu et all show that the proportion of salary to total compensation would increase with an increase in one or more of the following parameters: (i) uncertainty, (ii) marginal cost of production, and (iii) attractiveness of alternative job opportunities for the salesperson. Today's sales force play crucial roles and are considered essential and strategic for enhancing competitiveness and sales growth [6]. If the company wants to keep key employees they should provide a good and well balanced remuneration system. The question is what the key competencies in each position are and what remuneration is preferred and therefore motivating by the employees [7]. Kashi [8] solves a real-life application of multiple decision making methods in human resource practice also with focus on employees' performance evaluation. Performance appraisal is a process used by some firms to evaluate their employees' efficiency and productivity in order to plan their promotion policy, salary policy, layoffs policy, etc [9]. In such an evaluation process the reviewers evaluate some indicators related to employees' performance appraisal [9]. V. Y. Haines et S. St-Onge provides a support for the idea that performance management effectiveness is not only a function of system design or best practices, but also of programme implementation and execution in different organizational contexts. Although business leaders may be well advised to implement performance management training and other such practices, they should not neglect the possible influence of organizational culture or climate on overall performance management effectiveness [10]. In a public survey Deloitte conducted recently, more than half the executives questioned (58\%) believe that their current performance management approach drives neither employee engagement nor high performance. They, and we, are in need of something nimbler, real-time, an more individualized-something squarely focused on fueling performance in the future rather than assessing it in the past [11].

\subsection{Methods}

In the tasks of multi-criterial evaluation of variants there is defined a set of decision variants $X=\left\{X_{1}, X_{2}, \ldots, X_{\mathrm{n}}\right\}$ which are evaluated according to criteria $Y_{1}, Y_{2}, \ldots Y_{\mathrm{k}}$. According to these criteria each variant $X_{1}, i=1,2, \ldots, n$ is described by a vector of so-called criteria values $\left(y_{\mathrm{il}}\right.$, $\left.y_{\mathrm{i} 2}, \ldots y_{\mathrm{ik}}\right)$. The mathematical model of the multi-criterial variants evaluation can be expressed in the form of the criterion matrix [12].

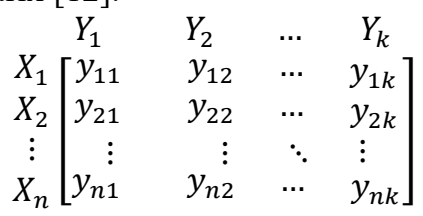

In the following practical study individual criteria have different weightings, in other words a different significance factor. After defining the criteria the next step is to determine the weights of the individual evaluation criteria. The criteria weights represent a numerical expression of the significance and importance of the observed KPI. It is necessary to standardize weights to achieve a comparability so that their sum is equal to the number one. A scoring method was used to determine the criteria weights which is to assign a certain number of points from the selected scale to each criterion according to how an assessor evaluates the significance of each criterion. 


\subsubsection{TOPSIS}

The Technique for Order of Preference by Similarity to Ideal Solution (TOPSIS) is a multicriteria decision analysis method. TOPSIS method is based on the selection of a variant which is closest to the so-called ideal variant which is characterized by the vector of the best criterion values and at the same time furthest from the so-called basal variant. It's the variant which is represented by the worst criterion vector [12].

Description of the method: The original $y_{\mathrm{ij}}$ criteria are transformed into $r_{\mathrm{ij}}$ values by relation

$$
r_{i j}=\frac{y_{i j}}{\left(\sum_{i=1}^{n} y_{i j}^{2}\right)^{\frac{1}{2}}}, i=1,2, \ldots, n ; j=1,2, \ldots, k
$$

The elements of normalized criterion matrix $W=\left(w_{i j}\right)$ are calculated as

where $v_{j}$ is the weight of $j$ criterion.

$$
\mathrm{w}_{i j}=v_{j} r_{i j}
$$

The ideal variant with the criterion values $\left(H_{1}, H_{2}, \ldots, H_{k}\right)$ and the basal variant with the values $\left(D_{1}, D_{2}, \ldots, D_{k}\right)$ are determined from the elements of the matrix $W$ where

$$
H_{j}=\max _{i}\left(w_{i j}\right) \text { and } D_{j}=\min _{i}\left(w_{i j}\right), i=1,2, \ldots, n \text {. }
$$

The distance of variants from ideal and basal variants are calculated according to relations

$$
\begin{aligned}
& d_{i}^{+}=\left[\sum_{j=1}^{k}\left(w_{i j}-H_{j}\right)^{2}\right]^{\frac{1}{2}}, i=1,2, \ldots, n . \\
& d_{i}^{-}=\left[\sum_{j=1}^{k}\left(w_{i j}-D_{j}\right)^{2}\right]^{\frac{1}{2}}, i=1,2, \ldots, n .
\end{aligned}
$$

Then indicator $c_{i}$ is calculated as the relative distance of variants from the basal variant:

$$
c_{i}=\frac{d_{i}^{-}}{d_{i}^{-}+d_{i}^{+}}, i=1,2, \ldots, n
$$

Values $c_{i}$ are from the interval $<0,1>$. They get 0 for the basal variant and 1 for the ideal variant. Variants can be arranged according to decreasing values $c_{i}$. For more detailed information please see [13].

\subsubsection{WSA}

Weighted Sum Approach is based on the construction of a linear utility function on a scale from 0 to 1 [12]. The worst variant according to a given criterion has the utility 0 , the best variant has the utility 1 and the other variants have utilities between these two extreme values [12]. This means that when applying this method, the elements of $y_{i j}$ of the input criterion matrix should be replaced by values $y_{i j}$ which will represent the utility $X_{i}$ in the criterion $Y_{j}$. The values $y_{i j}$ can be obtained for maximization criteria by the following relationship:

$$
\mathrm{y}_{i j}=\frac{y_{i j}-D_{j}}{H_{j}+D_{j}}
$$

Where $D_{j}$ is the lowest (in maximizing criterion the worst) and $H_{j}$ the highest (in maximizing criterion the best) criterion value $Y_{j}$. It is clear from the above equation that the utility $y_{i j}$ for the worst criterion value $y_{i j}=D_{j}$ is equal to 0 and for the best criterion value $y_{i j}=H_{j}$ is equal to 1 . The total utility of the variant $X_{i}$ is then calculated as the weighted sum of the partial utilities according to individual criteria.

$$
\mathrm{u}\left(X_{i}\right)=\sum_{j=1}^{k} v_{j} y_{i j}
$$

The variants can then be ordered by decreasing utility values $u\left(X_{i}\right)$.

\section{Salesforce evaluation}

The main task is to evaluate a group of salesforce staff by using multiple attribute decision making methods (MADM) to identify and reward the best ones. In the analysed company all sales executives are rewarded on the base of achievement of their business objectives. This 
following proposal extends the existing bonus system with a new extra bonus for the best employee. This new extra bonus is based on a competition for sales executives. The winner gains the biggest bonus and other less successful employees achieve a share of agreed bonus value according to their ranking. The purpose of this game is not just to win a bonus but also to feel an appreciation for their well done work and their achieved results and finally to get a comparison of individual employees in performance for general management purposes. The following scheme is designed such as a competition for sales staff in order to determine and reward the most successful workers on the base of their own performance for example in month or quarterly period. The evaluation procedure for identifying the best employee is a globally real-life situation in which the decision maker has to evaluate an employee according to several often inconsistent decision criteria [15]. These criteria are usually not consistent with each other, ie. the variant which is best rated for one criterion is not best rated for the other one [15]. Variants here are employees and criteria characterize these individual workers. Criteria include KPIs (Key Performance Indicators) on the Balanced Score Card base. In this decision problem there is several different criteria which are non-additive, (they are not in the same units of measure) [15]. It is a mixed set of criteria whose some characteristics are cardinal and some ones are ordinal. In world-wide practice the employees' evaluation is one of the real situation of multi-criterial decision making problems. The decision problem is an employees' evaluation, determination of preferential order and identifying the most successful player in this competition. As variants there were selected 11 players named anonymously as E1-E11 who compete together in business results achieved in various international markets. This group of players was evaluated by two different multiple attribute decision making methods - TOPSIS and WSA. Considering the purpose for which the evaluation was conducted, the following criteria were chosen as decisive: 1 . Sales increase [\%], 2. Gross margin [\%], 3. Customer retention [\%], 4. New customers [numbers], 5. New projects in existing customer accounts [numbers], 6. Customer satisfaction [\%], 7. Projects for saving costs [saving in CZK], 8. Subjective evaluation by manager [points]. The first seven criteria are cardinal, the last one is ordinal; evaluator assigned individual players by numbers $0-10$ according to her subjective evaluation on the basis of existing cooperation; 10 for the best, 0 for the worst. The criterial matrix according to Equation 1 with achieved results of KPIs of individual players is shown in Table 1. The normalized criterial matrix $\mathrm{R}$ which is derived from the original criterial matrix $\mathrm{Y}$ (Tab. 1) was recalculated according to Equation 2 and is shown in the Table 2.

Table 1. Criterial matrix Y - KPI's.

\begin{tabular}{|c|c|c|c|c|c|c|c|c|c|}
\hline \multirow{2}{*}{\multicolumn{2}{|c|}{$\begin{array}{l}\text { Criteria } \\
\text { MIN/MAX }\end{array}$}} & 1 & 2 & 3 & 4 & 5 & 6 & 7 & 8 \\
\hline & & MAX & MAX & MAX & MAX & MAX & MAX & MAX & MAX \\
\hline \multicolumn{2}{|c|}{ Points } & 7 & 10 & 10 & 6 & 6 & 10 & 2 & 5 \\
\hline \multicolumn{2}{|c|}{ Weights } & 0,13 & 0,18 & 0,18 & 0,11 & 0,11 & 0,18 & 0,04 & 0,09 \\
\hline \multirow{11}{*}{ 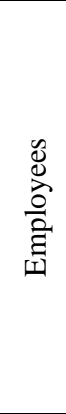 } & E1 & $10 \%$ & $45 \%$ & $100 \%$ & 0 & 1 & $85 \%$ & 32000 & 10 \\
\hline & E2 & $35 \%$ & $38 \%$ & $100 \%$ & 0 & 4 & $90 \%$ & 15000 & 10 \\
\hline & E3 & $5 \%$ & $37 \%$ & $88 \%$ & 1 & 2 & $80 \%$ & 0 & 7 \\
\hline & E4 & $21 \%$ & $53 \%$ & $100 \%$ & 1 & 1 & $90 \%$ & 50000 & 10 \\
\hline & E5 & $0 \%$ & $47 \%$ & $75 \%$ & 2 & 2 & $75 \%$ & 0 & 5 \\
\hline & E6 & $0 \%$ & $48 \%$ & $90 \%$ & 1 & 2 & $95 \%$ & 18000 & 7 \\
\hline & E7 & $1 \%$ & $32 \%$ & $96 \%$ & 3 & 2 & $70 \%$ & 0 & 5 \\
\hline & E8 & $12 \%$ & $0 \%$ & $90 \%$ & 1 & 1 & $85 \%$ & 0 & 6 \\
\hline & E9 & $2 \%$ & $36 \%$ & $100 \%$ & 0 & 3 & $80 \%$ & 41000 & 8 \\
\hline & E10 & $7 \%$ & $49 \%$ & $94 \%$ & 2 & 4 & $65 \%$ & 12000 & 8 \\
\hline & E11 & $0 \%$ & $39 \%$ & $85 \%$ & 0 & 1 & $90 \%$ & 0 & 5 \\
\hline
\end{tabular}


The Table 3 contains a matrix $\mathrm{W}$ which is derived from the matrix $\mathrm{R}$ by multiplying the relevant weights according to the Equation 3 then contains the ideal and basal variants according to the Formula 4, distances $d+$ and $d$ - from these variants calculated according to the Equation 5 and 6 and coefficients $c_{i}$ calculated according to the Equation 7 according to which employees are ranked.

Table 2. TOPSIS - normalized Criterial matrix R.

\begin{tabular}{|c|c|c|c|c|c|c|c|c|c|}
\hline \multicolumn{2}{|c|}{ Critera } & 1 & 2 & 3 & 4 & 5 & 6 & 7 & 8 \\
\hline \multicolumn{2}{|c|}{ MIN/MAX } & MAX & AAX & IAX & MAX & MAX & MAX & MAX & MAX \\
\hline \multicolumn{2}{|c|}{ Points } & 7 & 10 & 10 & 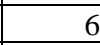 & 6 & 10 & 2 & 5 \\
\hline \multicolumn{2}{|c|}{ Weights } & 0,13 & 18 & 18 & 11 &, 11 &, 18 & 0,04 & 0,09 \\
\hline \multirow{11}{*}{ 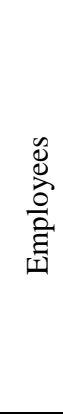 } & E1 & 0,2242 & 0,3317 & 0,3247 & 0,0000 & 0,1280 & 0,3097 & 0,4167 & 0,3962 \\
\hline & E2 & 7848 & 0,2801 & 0,3247 & 0,0000 & 0,5121 & 0,3279 & 0,1953 & 0,3962 \\
\hline & E3 &, 1121 & 0,2728 & 0,2857 & 0,2182 & 0,2561 & 0,2915 & 0,0000 & 0,2774 \\
\hline & E4 &, 4709 & 0,3907 & 0,3247 & 0,2182 & 0,1280 & 0,3279 & 0,6511 & 0,3962 \\
\hline & E5 & 0,0000 & 0,3465 & 0,2435 & 0,4364 & 0,2561 & 0,2733 & 0,0000 & 0,1981 \\
\hline & E6 &, 0000 & 0,3538 & 0,2922 & 0,2182 & 0,2561 & 0,3461 & 0,2344 & 0,2774 \\
\hline & E7 & 24 & 0,2359 & 17 & 0,6 & 0,2561 & 0,2551 & 0,0000 & 0,1981 \\
\hline & E8 & 691 & 0,0000 & 0,2922 & 0,2182 & 0,1280 & 0,3097 & 0,0000 & 0,2377 \\
\hline & E9 & 48 & 2654 & 3247 & 0,0000 & 0,3841 & 0,2915 & 0,5339 & 0,3170 \\
\hline & E1c & & 3612 & & & 0,5121 & & 0,1563 & 0,3170 \\
\hline & E11 & 0,0000 & 0,2875 & 0,2760 & 0,0000 & 0,1280 & 0,3279 & 0,0000 & 0,1981 \\
\hline
\end{tabular}

Table 3. TOPSIS - results.

\begin{tabular}{|c|c|c|c|c|c|c|c|c|c|c|c|c|}
\hline \multicolumn{2}{|c|}{ Criteria } & 1 & 2 & 3 & 4 & 5 & 6 & 7 & 8 & $d_{i}{ }^{+}$ & $d_{i}^{-}$ & $c_{i}$ \\
\hline \multirow{11}{*}{$\frac{0}{\stackrel{0}{0}}$} & E1 & 0,0280 & 0,0592 & 0,0580 & 0,0000 & 0,0137 & 0,0553 & 0,0149 & 0,0354 & 0,1072 & 0,0722 & 0,3997 \\
\hline & E2 & 0981 & 0500 & 0580 & 0,0000 & 0,0549 & 0,0586 & 0,0070 & 0,0354 & 0,0747 & 1211 & 6183 \\
\hline & E3 & 0,0140 & 0,0487 & 0,0510 & 0,0234 & 0,0274 & 0,0521 & 0,0000 & 0,0248 & 0,1044 & 0592 & 3582 \\
\hline & E4 & 0,0589 & 0,0698 & 0,0580 & 0,0234 & 0,0137 & 0,0586 & 0,0233 & 0,0354 & 0,0732 & 1010 & 5782 \\
\hline & E5 & 0,0000 & 0,0619 & 0,0435 & 0,0468 & 0,0274 & 0,0488 & 0,0000 & 0,0177 & 0,1305 & 0,0790 & 4169 \\
\hline & E6 & 0,0000 & 0,0632 & 0,0522 & 0,0234 & 0,0274 & 0,0618 & 0,0084 & 0,0248 & 0,1212 & 0,0728 & 0,3900 \\
\hline & E7 & 0,0028 & 0,0421 & 0,0557 & 0,0701 & 0,0274 & 0,0455 & 0,0000 & 0,0177 & 0,1061 & 0,0840 & 0,4368 \\
\hline & E8 & 0,0336 & 0,0000 & 0,0522 & 0,0234 & 0,0137 & 0,0553 & 0,0000 & 0,0212 & 0,1162 & 0,0440 & 0,2730 \\
\hline & E9 & 0,0056 & 0,0474 & 0,0580 & 0,0000 & 0,0412 & 0,0521 & 0,0191 & 0,0283 & 0,1179 & 0,0617 & 0,3403 \\
\hline & E10 & 0,0196 & 0,0645 & 0,0545 & 0,0468 & 0,0549 & 0,0423 & 0,0056 & 0,0283 & 0,0847 & 0,0932 & 0,5186 \\
\hline & E11 & 0,0000 & 0,0513 & 0,0493 & 0,0000 & 0,0137 & 0,0586 & 0,0000 & 0,0177 & 0,1366 & 0,0542 & 0,2904 \\
\hline \multicolumn{2}{|c|}{ Ideal } & 0,0981 & 0,0981 & 0,0580 & 0,0701 & 0,0549 & 0,0618 & 0,0233 & 0,0354 & & & \\
\hline \multicolumn{2}{|c|}{ Basal } & 0,0000 & 0,0000 & 0,0435 & 0,0000 & 0,0137 & 0,0423 & 0,0000 & 0,0177 & & & \\
\hline
\end{tabular}

The Table 4 contains results calculated by WSA. According to Equation 8 (for maximization criteria), the criterion matrix Y was normalized, and then, according to Equation 9, the utility of each employee was calculated. In the Table 5 there is a comparison of results calculated by both multiple attribute decision making methods. The table 6 includes a proposal of flexible bonus scheme for the top three best workers. These ones are given the opportunity to choose and vary the size of individual bonuses. They may choose to increase, decrease or end their current bonus and select new bonus from the menu provided. Generally the individualized flexible bonuses and adequate compensations of salesforce are significant factors in stimulating expansions to further global markets and generates further interdependence of salesforce motivation and business activities around the globe. 
Table 4. WSA - results.

\begin{tabular}{|c|c|c|c|c|c|c|c|c|c|c|}
\hline \multicolumn{2}{|c|}{ KPI } & 1 & 2 & 3 & 4 & 5 & 6 & 7 & 8 & Score \\
\hline \multirow{2}{*}{ Weights } & Abs. & 7 & 10 & 10 & 6 & 6 & 10 & 2 & 5 & 56 \\
\hline & Rel. & 0,1250 & 0,1786 & 0,1786 & 0,1071 & 0,1071 & 0,1786 & 0,0357 & 0,0893 & 1,0000 \\
\hline \multirow{11}{*}{ 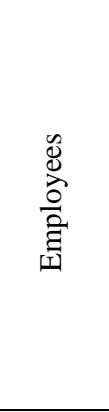 } & E1 & 0,2857 & 0,8491 & 1,0000 & 0,0000 & 0,0000 & 0,6667 & 0,6400 & 1,0000 & 0,5971 \\
\hline & E2 & 1,0000 & 0,7170 & 1,0000 & 0,0000 & 1,0000 & 0,8333 & 0,3000 & 1,0000 & 0,7876 \\
\hline & E3 & 0,1429 & 0,6981 & 0,5200 & 0,3333 & 0,3333 & 0,5000 & 0,0000 & 0,4000 & 0,4318 \\
\hline & E4 & 0,6000 & 1,0000 & 1,0000 & 0,3333 & 0,0000 & 0,8333 & 1,0000 & 1,0000 & 0,7417 \\
\hline & E5 & 0,0000 & 0,8868 & 0,0000 & 0,6667 & 0,3333 & 0,3333 & 0,0000 & 0,0000 & 0,3250 \\
\hline & E6 & 0,0000 & 0,9057 & 0,6000 & 0,3333 & 0,3333 & 1,0000 & 0,3600 & 0,4000 & 0,5674 \\
\hline & E7 & 0,0286 & 0,6038 & 0,8400 & 1,0000 & 0,3333 & 0,1667 & 0,0000 & 0,0000 & 0,4340 \\
\hline & E8 & 0,3429 & 0,0000 & 0,6000 & 0,3333 & 0,0000 & 0,6667 & 0,0000 & 0,2000 & 0,3226 \\
\hline & E9 & 0,0571 & 0,6792 & 1,0000 & 0,0000 & 0,6667 & 0,5000 & 0,8200 & 0,6000 & 0,5506 \\
\hline & E10 & 0,2000 & 0,9245 & 0,7600 & 0,6667 & 1,0000 & 0,0000 & 0,2400 & 0,6000 & 0,5665 \\
\hline & E11 & 0,0000 & 0,7358 & 0,4000 & 0,0000 & 0,0000 & 0,8333 & 0,0000 & 0,0000 & 0,3516 \\
\hline
\end{tabular}

Table 5. Comparison - TOPSIS vs WSA.

\begin{tabular}{|c|r|c|r|}
\hline \multicolumn{2}{|c|}{ TOPSIS } & \multicolumn{2}{c|}{ WSA } \\
\hline$c_{i}$ & Employee & Score & Employee \\
\hline 0,6183 & E2 & 0,7876 & E2 \\
\hline 0,5782 & E4 & 0,7417 & E4 \\
\hline 0,5186 & E10 & 0,5971 & E1 \\
\hline 0,4368 & E7 & 0,5674 & E6 \\
\hline 0,4169 & E5 & 0,5665 & E10 \\
\hline 0,3997 & E1 & 0,5506 & E9 \\
\hline 0,3900 & E6 & 0,4340 & E7 \\
\hline 0,3582 & E3 & 0,4318 & E3 \\
\hline 0,3403 & E9 & 0,3516 & E11 \\
\hline 0,2904 & E11 & 0,3250 & E5 \\
\hline 0,2730 & E8 & 0,3226 & E8 \\
\hline
\end{tabular}

Table 6. Flexible bonus proposal.

\begin{tabular}{|c|c|c|}
\hline \multicolumn{3}{|c|}{ Flexible monthly bonus proposal } \\
\hline Ranking & Avarage daily salary & Paid day off \\
\hline 1 & 3 days & 3 days \\
\hline 2 & 2 days & 2 days \\
\hline 3 & 1 days & 1 days \\
\hline
\end{tabular}

\section{Summary and conclusion}

Practically every employee undergoes an evaluation. In this practical part, attention was focused on sales executives operating world-wide and on the evaluation of their achieved hard results - values of performance indicators of pre-set goals and on a subjective evaluation made by their business manager or business director depending on the organizational structure. The purpose of this evaluation was to compare sales executives among themselves according to several inconsistent criteria with a different significance factor by using multiple attribute decision making methods. TOPSIS and WSA are useful techniques for solving reallife multi-criterial decision problems such employees' evaluations are. In Section 2, I showed through examples how to determine who is the best and who is the worst in comparing with others and how to rank them to reward the most successful ones. Focusing on criteria set out in the practical study both used methods (TOPSIS and also WSA) showed the same winner and the same less successful employee. In the comparison of both used methods the ranking of other employees deviates which is caused by a different calculation methodology. It means in the evaluation process both methods should give us the same results in the first and in the last place but the ranking of others can very probably deviate. Therefore, for a long-term repetitive practical usage, it is appropriate to use constantly one method to ensure a consistent procedure and a fair evaluation for employees. Using TOPSIS method there is needed more 
calculations comparing with WSA. WSA was quicker and easier to process. But both methods provide an effective tool for solving multi-criterial assessment.

Rewarding of the best employees was proposed based on flexible bonuses. The advantage is a possibility of individual choice or a combination for rewarded employees. On the menu the employee can choose between a financial bonus or paid time off. The bonuses may be combined, changed and end at will and according to employees' needs. Assessing the past is undoubtedly important and brings facts for further decision-making. The question is what is the driving force that will affect employees' future results. The only thing is certain, the driving force must be individualized to the needs of a concrete employee to make an effect. In today's era of globalization and its socio-economic consequences every employer requires flexible sales executives, a sales executive expects also the flexible approach from the employer - flexible bonuses and benefits and flexible working conditions such as homeoffice, flexible working hours. All these trends are connected with work life balance. This trend helps with low rate of fluctuation, higher attractiveness of the employer and stabilising with key employees [15].

The limitation of the evaluation in this practical study is that in achieved results there is not mentioned sales executives' difficulties and barriers in individual international markets. Each of these researched sales executives operates in a different international market, care about a different number of customer accounts and each one must overcome a different market barriers in doing the international business. In specific foreign and overseas business markets, their work is hampered by the local business practices, religious traditions, mentality and behaviour of local businessmen which are often very different from European ones. These aspects also significantly influence the results of sales executives' works. So there is a question if results of all sales executives with different sales areas in the world can be comparable. These mentioned facts maybe can caused the comparison of salesforce staff look a little bit not objectively, considering also others factors than the criteria involving only values of KPI's mentioned in the practical study, such as various international trade barriers, the necessity of the adoption of local business practices and customs and sensitivity of respecting local rules and religion. Not everybody is suitable for every sales area. But as an argument can be the fact that each sales executive is or should be selected for such a sales area for which he/she has the best assumptions, or experience already gained, respectively personal links to business partners on a concreate market abroad. These business experience and relationships have been creating and forming a long time, sometimes several years, before they start to generate profits. So this is a next limitation factor of the evaluation which would be appropriate also consider. As a further specific issue in the evaluation process can be the case when a sales executive can make an intensive and excellent job and can start the successful business but which can bring profit a few years later but until this time he would be unfairly evaluated as an outsider. This one should be evaluated in a special group of new business development managers with own specific criteria. In a further scientific research it would be beneficial to focus on these limitation factors and try to involve them into the evaluation process.

This article was prepared as a part of the SGS project at the Faculty of Economics, VŠB-TU Ostrava, the project number: SP2019/7.

\section{References}

1. M. Armstrong, Handbook of Employee Reward Management and Practice. (Kogan Page Publishers, UK, 2007) 
2. L. Lidinska, J. Jablonsky, AHP model for performance evaluation of employees in a Czech management consulting company. Central European Journal of Operations Research, 26, 239-258 (2018)

3. E. Ghauri, Performance evaluation of sales employees: a comparative investigation in the pharmaceutical industry. International Journal of Business Performance Management, 19, 253-279 (2018)

4. L.F. Pitt, M.T. Ewing, P.R. Berthon, Proactive behavior and industrial salesforce performance. Industrial Marketing Management, 31, 639-644 (2002)

5. A.K. Basu, R. Lal, V. Srinivasan, R. Staelin, Salesforce Compensation Plans: An Agency Theoretic Perspective. Marketing Science, 4, 267 (1985)

6. G.K. Amoako, B.K. Okpattah, Unleashing salesforce performance: The impacts of personal branding and technology in an emerging market. Technology in Society, 54, 2026 (2018)

7. K. Kashi, P. Horvathova, MADM methods in practice: Linking competencies to employees' appraisal and total reward. Proceedings of the 15th European Conference on Knowledge Management, 15, 1229-1239 (2014)

8. K. Kashi. Applying group decision making methods in human resources. Innovation Vision 2020: From Regional Development Sustainability to Global Economic Growth. 25 1980-1989 (2015)

9. R. de Andres, J.L. Garcia-Lapresta, J. Gonzalez-Pachon, Performance appraisal based on distance function methods. European Journal of Operational Research, 207, 15591607 (2010)

10. V.Y. Haines, S. St-Onge, Performance management effectiveness: practices or context? International Journal of Human Resource Management, 23, 1173-1180 (2012)

11. M. Buckingham, A Goodall, Reinventing performance management. Harvard Business. Review, 93, 40-46 (2015)

12. J. Jablonsky. Operacni vyzkum. (Professional Publishing, Czech Republic, 2007)

13. P. Fiala, J. Jablonsky, M. Manas. Vicekriterialni rozhodovani. (VSE, Czech Republic, 1994)

14. G. Polakova, Multi-criteria decision making methods in salesforce recruitment. Ekonomicky a financni vyzkum - prezentace vysledku doktorandu. 6, (to be published)

15. M. Adamova, N. Soukupova, E. Dostalova, R. Krninska, Modern trends in human resource management. Globalization and Its Socio-Economic Consequences. Rajecke Teplice, Slovakia, 18, 4 (2018) 